



\section{sentidos do anhangabaú}

pablo emilio robert hereñú

orientadora profa. dra. regina maria prosperi meyer

dissertação de mestrado

universidade de são paulo

faculdade de arquitetura e urbanismo

são paulo, fevereiro de 2007 

para natalia e beatriz 



\section{Agradecimentos}

Regina Maria Prosperi Meyer, pela confiança

Eduardo Rocha Ferroni e Fernanda Costa Neiva, pelo companheirismo

Silvia Amstaldem Franco, pela enorme força

Fernando Mello Franco e José Geraldo Simões Jr., pela banca de qualificação

César Shundi, pelas conversas e pela disposição

Beatriz Hereñú e Marilena Alves pelas traduções e revisões

Funcionários da biblioteca FAUUSP, pela paciência

Colegas que, direta ou indiretamente, colaboraram com esta pesquisa

Cooperantes, pelo suporte

Badu, pela companhia

Natália Alves Barbieri, por tudo 



\section{Resumo}

Esta dissertação trata dos projetos, construídos ou não, relacionados de algum modo ao Vale do Anhangabaú, no Centro Histórico de São Paulo. A partir de uma matriz de leitura, foram selecionadas e estudadas propostas, pontuais ou gerais, que de alguma maneira contribuíram para a construção da cultura arquitetônica sobre aquele recinto.

A metodologia adotada baseou-se na leitura de projetos, utilizando preferencialmente como material de sustentação das análises os elementos gráficos originais de sua representação e a edição destes, com o objetivo de explicitar determinados aspectos. A partir dessas leituras foram identificadas cinco questões norteadoras das propostas para o vale: barreira, lugar, passagem, conflito e resíduo. Uma reflexão sobre as transformações ocorridas ao longo desses cinco momentos conclui o trabalho, buscando subsidiar a discussão atual sobre o Anhangabaú e o desafio que este coloca para a cidade.

\section{Resumen}

Esta disertación trata de los proyectos, construídos o no, relacionados de alguna manera al Vale do Anhangabaú en el Centro Histórico de São Paulo. Fueron seleccionadas y estudiadas propuestas, puntuales o generales, que de alguna manera contribuyeron para la construcción de la cultura arquitectónica de aquel recinto.

La metodología adoptada tuvo como base la lectura de proyectos, utilizando preferentemente como material de sustentación de análisis los elementos gráficos originales de su representación y la edición de éstos, con el objetivo de tornar explícitos determinados aspectos. A partir de esas lecturas fueron identificados cinco temas generales que nortearon las propuestas para el valle: barrera, lugar, pasaje, conflicto y residuo. Una reflexión sobre las transformaciones ocurridas a lo largo de esos cinco momentos concluye el trabajo, buscando subsidiar la discusión actual sobre el Anhangabaú y el desafío que éste coloca para la ciudad.

\section{Abstract}

This dissertation deals with the projects, built or unbuilt, related directly or indirectly to Vale do Anhangabaú in the Historical Center of São Paulo. Proposals which contributed in some way to the construction of the architectural culture of the site, both small-scale and general, were selected and analyzed.

The methodology adopted was based on the reading of projects, preferentially using as supporting material the original graphic elements for their representation and their edition, with the objective of making explicit some determined aspects. From these readings, five questions were identified, which characterize the proposals for the valley: barrier, place, passage, conflict and residue. A reflection on the transformations occurred during those five moments concludes the work, aiming to give support to the present discussion about Anhangabau and the challenge it poses to the city. 



\section{Sumário}

\section{Introdução 13}

O vale como barreira $\quad 17$

A colina histórica 19

As ferrovias e a expansão do centro 23

Jules Martin e o Viaduto do Chá [1877/1892] 31

Alberto Kuhlmann e "Linha Férrea Elevada" [1888]

Viaduto Santa Efigênia [1890/1913] 53

\section{O vale como lugar $\quad 59$}

Vislumbrando um lugar 6

Os "melhoramentos" e os primórdios do urbanismo em São Paulo

A contribuição de Adolfo Augusto Pinto [1890]

Um grande palco: teatros São José e Municipal [1903/1911]

As indicações do Vereador Augusto Carlos da Silva Telles [1907]

Alexandre de Albuquerque e os investidores privados [1910]

87

Victor da Silva Freire, Eugênio Guilhem e a contribuição municipal [1911]

Samuel das Neves e a proposta do Governo Estadual [1911]

O "Relatório Bouvard" e o encerramento da disputa [1911]

101

Viaduto São João [1912] 113

A nova "cara" do vale: os Neves imprimem sua marca

Monteiro Lobato e o "Ruaduto" do Chá [1913] 



\section{O vale como passagem 143}

Mobilidade e cidade $\quad 145$

Túneis sob a colina histórica [1914] 155

Projeto Light [1927] 159

A imagem de Le Corbusier para São Paulo [1929]

Prestes Maia e o Anhangabaú

Rino Levi e o centro 197

O novo Viaduto do Chá [1935]

\section{O vale como conflito 223}

O automóvel e o Anhangabaú 225

Os anos 50 e 60 na Europa 229

O Metrô no vale: estações São Bento e Anhangabaú

A megaestrutura de Nestor Goulart Reis Filho [1972]

O Anhangabaú de Artigas [1974] 255

Uma década de indecisões da EMURB

Concurso Anhangabaú [1981]

\section{O vale como resíduo}

\section{3}

À procura de um sentido

O Novo Anhangabaú $\quad 327$

Projetos recentes

339

O vale como desafio (considerações finais)

Evolução do recinto 353

Construções, destruições... 367

$O$ vale como desafio de projeto

369 


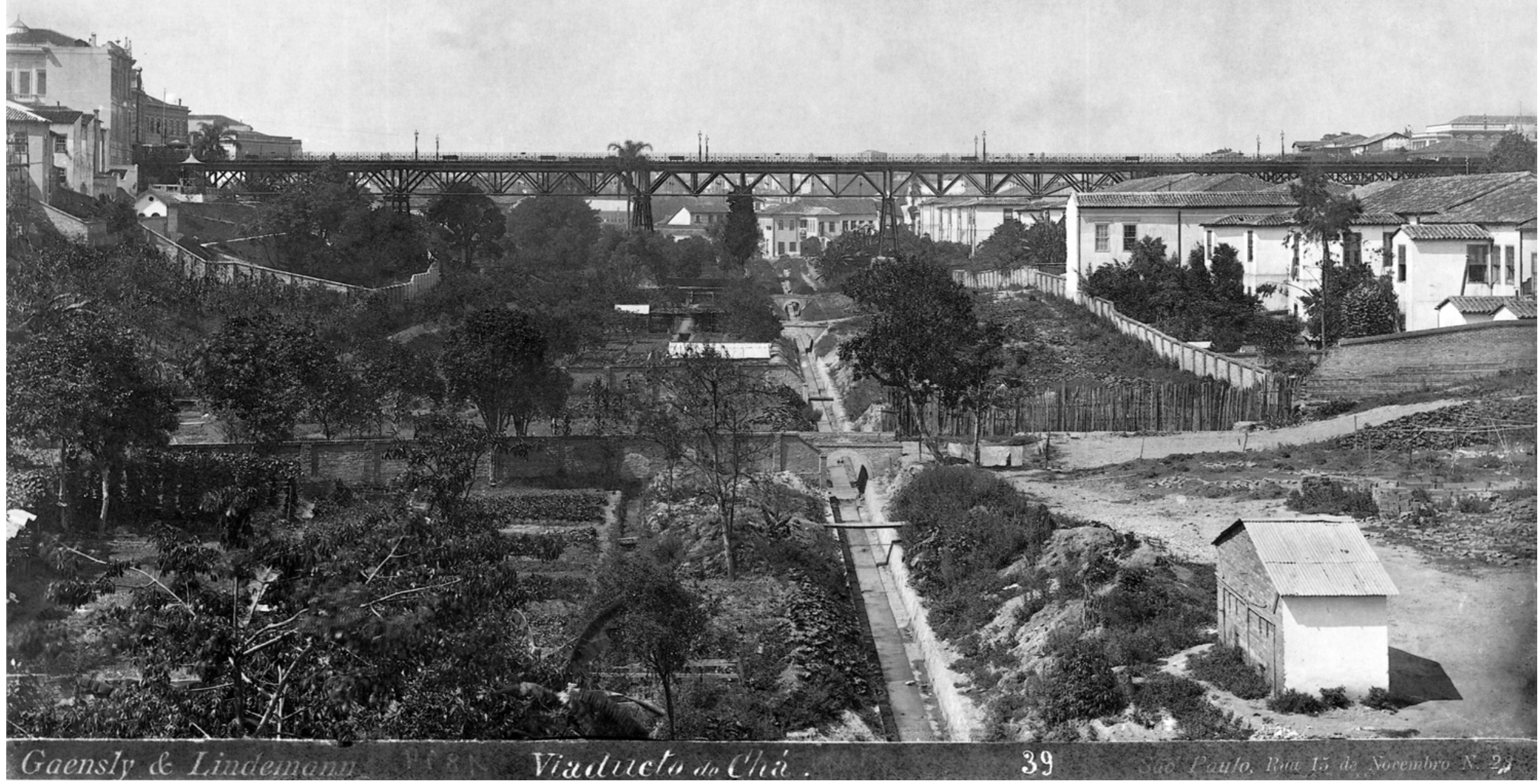




\section{Introdução}

Fig.1

Vista do Anhangabaú e do Viaduto do Chá a partir do Acu (São João). Gaensly\&Lindemann. [TOLEDO, Benedito Lima de. Prestes Maia e as Origens do Urbanismo Moderno em São Paulo. São Paulo: Empresa das Artes, 1996. p.173.]
O Vale do Anhangabaú, espaço singular da cidade de São Paulo, já foi, há algumas décadas, um dos locais mais representativos da metrópole, reconhecido por sua população como um símbolo e uma referência. Atualmente se configura como um espaço ambíguo que mescla a grandeza de seu passado, cristalizada no importante acervo arquitetônico ali implantado, a estagnação de seu presente e a incerteza em relação a seus possíveis futuros. Este é o aspecto que despertou a curiosidade que originou esta pesquisa.

Para os arquitetos e urbanistas paulistanos, o vale desempenhou historicamente o papel de um grande laboratório, sendo objeto de planos e projetos desde os primeiros momentos em que essas atividades, a arquitetura e o urbanismo, se estabeleceram em seu território. O conjunto de propostas resumidas neste volume representa o empenho de boa parte dos mais significativos profissionais que atuaram em São Paulo, entre os quais encontram-se figuras como Victor da Silva Freire, Ramos de Azevedo e sua equipe de arquitetos, Carlos Ekman, Samuel e Cristiano Stockler das Neves, Joseph Antoine Bouvard, Hipólito Pujol, Victor Dubugras, Norman Wilson, Le Corbusier, Francisco Prestes Maia, Elisário Bahiana, Gregori Warchavchik, Lucjan Korngold, Oscar Niemeyer, Giancarlo Palanti, Rino Levi, Vilanova Artigas e Paulo Mendes da Rocha. Sob essa perspectiva, o Anhangabaú pode ser considerado uma espécie de "vitrine" da arquitetura e do urbanismo em São Paulo.

O rumo da investigação que resultou nesta dissertação foi direcionado pela surpreendente quantidade de material disponível sobre o assunto contida em trabalhos acadêmicos, livros, revistas e arquivos de instituições públicas. Coletar, organizar e disponibilizar esse conteúdo foi um dos objetivos do trabalho.

A matriz de leitura que levou à seleção definitiva das proposições estudadas foi sendo moldada ao longo da pesquisa, conforme as questões suscitadas pela documentação levantada. Finalmente foram destacados os projetos que, de modo significativo, possam ter contribuído para a formação da cultura urbanística e do repertório arquitetônico específicos da cidade e daquele recinto em especial, independentemente de terem sido ou não construídos. 


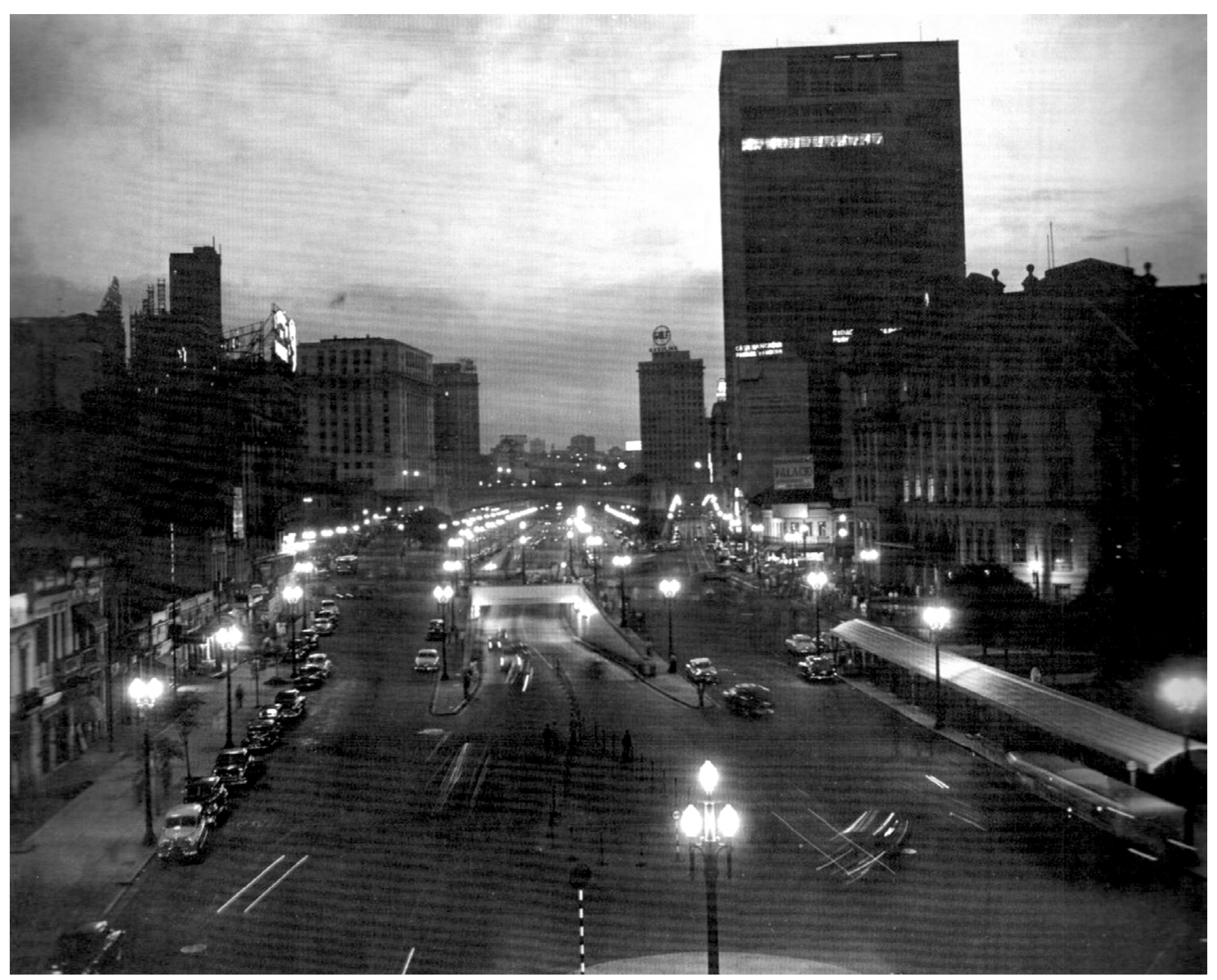


Como se fosse uma novela constituída de contos, a estruturação da dissertação procurou construir uma reflexão que se desenvolve ao longo do trabalho como um todo, preservando, no entanto, a possibilidade de leitura de cada um dos projetos em seus universos particulares. Deste modo, as imagens inseridas no caderno não tem como função primordial a ilustração do texto, mas sim a de construir um discurso próprio. Pretende-se com isto abrir espaço para leituras menos direcionadas dos projetos apresentados de modo a propiciar interpretações diferentes e eventualmente opostas às que se encontram nas páginas a seguir.

Os capítulos que compõem este trabalho surgiram da interpretação das abordagens e das premissas gerais que nortearam os projetos para o vale ao longo de sua história. A partir disso, cinco momentos distintos foram identificados, nos quais o sentido conferido ao Anhangabaú tinha um caráter específico:

o vale como barreira;

o vale como lugar;

o vale como passagem;

o vale como conflito;

o vale como resíduo.

As considerações finais são acompanhadas de uma seqüência gráfica de análise das transformações do vale, vividas e projetadas, ao longo do tempo, que tem a intenção de levantar possíveis caminhos para o enfrentamento das questões que o Anhangabaú apresenta hoje para a cidade e seus arquitetos. O vale como desafio. 
